\title{
Discurso, argumentación y educación
}

\author{
Discourse, Argumentation and Education
}

Alfonso Cárdenas*

Recibido: 22 de octubre de 2012

Aceptado: 19 de noviembre de 2012

\section{Resumen}

El objetivo de este artículo es formular un marco teórico bajtiniano que, a la vez que sustente la argumentación, sirva de base para desarrollar una pedagogía que apoye la enseñanza del pensamiento y la interacción, como procesos pedagógicos del lenguaje. Al final, plantea varias conclusiones que pueden ser útiles para la enseñanza discursiva del lenguaje.

Palabras clave: pedagogía, discurso, texto, mediación, argumentación.

\section{Abstract}

The paper proposes a bakhtinian theoretical framework for argumentation; also, it formulates some strategies for guiding the pedagogical work with the speech. In the end, it suggests several conclusions that can be useful for language teachers.

Key words: pedagogy, speech, text, mediation, argumentation.

\section{Introducción}

En la actualidad uno de los retos educativos concierne a la problemática de la información y del conocimiento. En ella, el interés pedagógico ha de concentrarse en las características de la actual sociedad, en la cual los esquemas, los modelos, la sistematización, las operaciones discursivas, las estructuras cognitivas son temas que llaman la atención de los educadores. No obstante, son las formas de razonamiento y los procedimientos comprensivos y, en especial, las relaciones entre el conocimiento dado y el construido, las piezas que nos importan con respecto a la argumentación. Adicionalmente, nos interesan los valores éticos que comprometen socialmente a las personas, tanto en razón de sus interacciones y posiciones mutuas como de la autoconciencia, la responsabilidad y la expresión en cada uno de los actos de la vida.

La relevancia de estos asuntos con respecto a la argumentación obedece a que la racionalidad dialógica (Habermas, 1989) ha provocado, por un lado, el quiebre de la representación (Bruner, 1989) y, por otro, ha contribuido a generar espacios de entendimiento y diversificado los vínculos racionales con otras tantas mediaciones,

* Magíster en Literatura, magíster en Lingüística y doctor en Literatura de la Universidad Javeriana. Profesor de la Universidad Pedagógica Nacional de Bogotá, Colombia. Correo electrónico: acardena@pedagogica.edu.co 
así como los campos del accionar humano, en sus nexos con el mundo, con los demás y con el hombre mismo, con la esperanza de darle sentido a la vida. Por la misma razón, han cambiado las relaciones con el conocimiento y los saberes cuya pluralidad exige discusión, adhesiones, consensos y apoyos que suscitan acuerdos pero también provocan controversias. Este es, grosso modo, el horizonte discursivo en el cual se mueve la argumentación, ya se trate de demostrar, de acotar evidencias, o de convencer y persuadir.

Teniendo en cuenta lo anterior, el objetivo central de este artículo es desarrollar algunas líneas de la investigación DLE-033-99, ${ }^{1}$ según la cual, la perspectiva semiodiscursiva y sociocognitiva del lenguaje debe prestar atención a varios factores pedagógicos que, con respecto a ciertos niveles de competencia básica, ha de entenderse con el conocimiento y la interacción, así como abordar los problemas del razonamiento y la comprensión con base en la diversidad discursiva del texto. El propósito es consolidar un marco teórico que oriente la enseñanza del lenguaje para la vida, para el aprendizaje y como objeto de conocimiento, desde una pedagogía integral que se interese en los procesos de pensamiento e interacción (Cárdenas, 1997, 2012c), desde el discurso argumentativo.

En particular, nos interesa situar la argumentación en el marco semiodiscursivo de la investigación y desarrollar algunos lineamientos en torno a algunas manifestaciones cognitivas y discursivas, con respecto a las cuales el enfoque lingüístico puede resultar insuficiente.

1 Esta investigación se conoce bajo el nombre de "Un marco semiótico-discursivo y sociocognitivo para la enseñanza del lenguaje". Ha sido patrocinada por el Centro de Investigaciones de la Universidad Pedagógica Nacional (UPN-CIUP).

\section{Acercamiento a la argumentación}

Si aceptamos que el hombre razona de manera formal y práctica, que los modos de la causalidad son diversos, que está sujeto a diversas mediaciones, etc., se puede plantear que la argumentación es una suerte de retórica que, además de atender a los juegos de lenguaje sobre sí mismo, insiste en referirse al mundo desde la perspectiva múltiple de causas, razones y motivos; por eso, su fuerte es la causalidad en sus instancias lógica, física o psicológica. La variedad de enfoques que resulta la hacen indispensable tanto en la vida académica como en la vida práctica de las personas. Por eso, la argumentación es un proceso cognitivo y también un tipo de razonamiento, al tiempo que es un medio de acción social y una manifestación evidente de la naturaleza retórica y dialógica del lenguaje.

Como proceso cognitivo, hace acopio de conceptos e imágenes desde los cuales expresa relaciones, realiza operaciones y efectúa explicaciones e interpretaciones con miras a desplegar un tema. Como proceso de razonamiento, apela a fundamentos y principios que apoyan las demostraciones o las pruebas; diversifica la mirada para apoyarse en motivos tendientes a verificar hipótesis o sustentar una tesis, con base en razones o evidencias, o reflexionar sobre las hipótesis, dentro del amplio juego de articulación que nos ofrecen la inducción, la deducción, la abducción y la transducción. En calidad de proceso retórico, pone en ejecución múltiples procedimientos expresivos y manifiesta la capacidad autorreflexiva del lenguaje; en fin, como proceso discursivo, la argumentación es una práctica dialógica que pone en paralelo puntos de vista divergentes para relacionarlos, compararlos, contrastarlos, apoyando unos en otros, con el fin de suscitar el consenso o la controversia entre ellos.

Este complejo campo obedece a la diversidad típica de la acción humana y al hecho de que argumentalmente no hay patrones preestablecidos; por ello es 
una buena decisión apelar a la resolución de problemas con la ayuda del lenguaje. Esto es así porque el universo del hombre no se define solamente por su carácter declarativo o de constatación; es decir, no se caracteriza solamente por la necesidad de las demostraciones propias del discurso declarativo. La vida cotidiana de los seres humanos se caracteriza por estar llena de preguntas y por solicitar respuestas, por atenazar la realidad desde diversos ángulos y puntos de vista; por la mirada ideológica y escéptica pero, a la par, por la búsqueda de ciertas seguridades, de estribos, de conclusiones.

Lo cierto es que el recorte formal y el rigor lógico que se hace del lenguaje, obedeciendo a propósitos lógicos sometidos al contexto global, no es tan natural y solo responde a un discurso global que privilegia lo asertórico, lo objetivado con las pretensiones de dirigirse a todo el mundo, al margen de valores e ideologías. Pero el ser humano se caracteriza por los valores que produce, por crear un mundo condicionado y sometido a las restricciones del entorno; esta es la razón por la cual nuestro punto de vista discursivo trata de situarse dentro de un enfoque contextual del sentido como significación y valor (Bajtín, 1997).

Por tanto, si nos atenemos al sentido, la argumentación es un proceso abierto cuya finalidad no está definida y, por tanto, puede trabajarse en varias direcciones: lógica, analógica y dialógica (Cárdenas, 2012a).

\section{Principios de la argumentación}

De acuerdo con lo dicho, la argumentación ${ }^{2}$ puede orientarse hacia la demostración, ${ }^{3}$ la verificación o la explicación (Cárdenas, 1997). No obstante, el interés de esta investigación se concentra en las estrategias

2 Las líneas generales de este planteamiento se encuentran en Chauraudeau (1983) y Perelman y Olbrecchts-Tyteca (1989).

3 El enfoque demostrativo de la argumentación puede ser consultado en Correa et al. (1999). analógicas (Beuchot, 1997) y dialógicas utilizadas para convencer o persuadir, de manera que la posición esbozada se ajusta parcialmente a la visión retórica planteada por Perelman y Olbrecchts-Tyteca (1989) y a la dialógica de Bajtín (1992), para reconocer que las fronteras entre lo lógico, analógico y dialógico no son claras (Cárdenas, 2012a, p. 154). Por eso, la argumentación puede servir para establecer la verdad o la validez de un planteamiento; convencer de la razón, la plausibilidad o la conveniencia de un hecho, concepto, fenómeno, actividad, etc.; defender un punto de vista, sustentar una tesis o mover a la acción. Estos propósitos de la conducta argumentativa toman en cuenta los campos lógico y analógico del sentido e incorporan el vasto horizonte de las mediaciones humanas que rigen el comportamiento humano.

Se puede plantear, entonces, que el campo de la argumentación se extiende tanto al pensamiento formal, en el que el conocimiento es impersonal, como al pensamiento no formal, que gira en torno a valores y responde a propósitos de los sujetos discursivos. En este sentido, el discurso argumental es un acto de habla complejo cuya intención puede ser demostrar una tesis, persuadir a un auditorio de un planteamiento digno de ser asentido o impugnado o de emprender cierta acción, o convencer según la bondad de principios racionales de aceptación general. ${ }^{4}$

En atención a lo dicho, la argumentación funciona cuando facilita la sustentación de una tesis, ya sea que falten o no la demostración rigurosa o la prueba experimental; ofrece soportes para persuadir a un auditorio o grupo científico de que la tesis demostrada o verificada es válida; proporciona criterios para

4 Los principios en que se basa la argumentación pueden ser compartidos por la mayoría de personas o por especialistas en el ámbito respectivo; por su carácter pragmático, pueden ser plausibles y no necesariamente verdaderos o válidos. La verdad o la validez de los principios dan lugar a la demostración o a la verificación experimental. 
sostener interpretaciones dadas en la investigación sobre bases admisibles por la comunidad científica; contribuye a hacer verosímil lo que se propone y a justificar un planteamiento o curso de una acción; induce a tomar decisiones y a emprender acciones acordes con lo que se plantea. ${ }^{5}$

\section{El campo discursivo de la argumentación}

La argumentación configura un campo discursivo que revela a todas luces la capacidad mediadora del lenguaje y su poder de referenciar. Este papel corresponde al aparato argumentativo ${ }^{6}$ cuya organización gira en torno a estructuras lógicas, dimensiones textuales y operaciones discursivas (Charaudeau, 1983). Las estructuras lógicas -conjunción, disyunción, oposición y causalidad-definen un primer campo de ejercicio del razonamiento lógico. No obstante, al frente aparece la analógica, la cual da lugar a un nutrido grupo de estrategias argumentativas que, más allá de la demostración o la verificación de hipótesis, abren espacio al razonamiento sobre las hipótesis (Cárdenas, 2011b) o al razonamiento holístico o crítico (Cárdenas, 2011c). Por medio de ellos, la argumentación elabora un dispositivo en el que alternan diferencias y sincretismos que, además de prevenir la contradicción, dan lugar a alternativas en las que prevalecen la causalidad psicológica, la posibilidad, la toma de decisiones, el descubrimiento de hipótesis o la adivinación. Cada una de estas formas se muestra proclive a disociar las estructuras lógicas.

El segundo vector concierne a los factores textuales - dinámica, cohesión y coherencia- que organizan

5 De acuerdo con la dimensión ética del hombre y el pensamiento crítico, así como con el proceso pedagógico de la interacción, esta última función argumentativa es fundamental en los procesos de participación y acción crítica.

6 En la semiolingüística se distinguen, además de este, otros aparatos conceptuales del discurso, como el enunciativo, el retórico y el narrativo (Cárdenas, 2000a). la estructura discursiva del argumento alrededor de la composición; las relaciones diafóricas; la conexión; las sustituciones, repeticiones y transformaciones; la estructura de la información o la disposición textual de la información en conjuntos, esquemas o secuencias, en los que claramente están implicados elementos que exigen prestar atención al texto. El tercer mecanismo se refiere a las operaciones discursivas (lógicas y analógicas) mediante las cuales se elimina la neutralidad de las formas del pensamiento y se enriquece la información desde posturas subjetivas expuestas a través de puntos de vista, modalidades y perspectivas que involucran elementos de orden sintáctico, semántico y pragmático.

Acorde con lo dicho, la argumentación no extraña ninguno de los componentes que nuestra investigación ha puesto en la comprensión del lenguaje, ya sean de índole semiótica, discursiva, social o cognitiva. Por lo mismo, exige atender al pensamiento (Cárdenas, 2000b) en sus vertientes: lógicadialéctica, analógica-analéctica y dialógica-crítica (Cárdenas, 2012a) y a la diversidad de formas del razonamiento: inducción, deducción, abducción y transducción, según el marco de nuestra investigación (Cárdenas, 2011b, 2011c). En esta dirección, la práctica argumentativa es irreductible a formas lógicas o puramente retóricas (Monsalve, 1997; Perelman y Olbrecchts-Tyteca, 1987), lo cual es una respuesta al quiebre de la representación.

Según se verá más adelante, la argumentación es una manifestación dialógica que, en procura de la eficacia discursiva, se apoya en el sentido en torno al cual mantiene un papel de mediación que dispersa la discusión en varios frentes de las relaciones: yo-yo, yo-otro, yo-mundo.

\section{El quiebre de la representación}

La argumentación es una forma de poner a prueba el saber-pensar y el saber-decir del mundo y, por tanto, 
una forma de introducir la diversidad polifónica en el lenguaje y de poner en escena la discursividad ideológica y valorativa de los sujetos discursivos. De ser así, no cabe duda de que es preciso tomar distancia de las pretensiones de la representación (Rojas, 2006), máxime cuando algunos estudiosos alegan, confinados en un horizonte discursivo estrecho, que el lenguaje no representa la realidad.

Frente al contraste planteado, es necesario afirmar a vuelo de pájaro y en primer lugar que el discurso no es un proceder puramente lógico o lingüístico que se ajuste a una conciencia previa y se apoye en estructuras y categorías lógicas. En segundo lugar, que el lenguaje no transmite en propiedad mensajes, porque el mensaje no obedece necesariamente a una intención precedente, como tampoco se estructura según un código acordado con anticipación, cuya interpretación implique su cierre. Tercero, que el discurso es ideológico, lo cual supone que, además de proponer ideas, propone valores (énfasis, acentos, focos, perspectiva, puntos de vista) en torno a esas ideas. Cuarto, que el lenguaje crea referencias en torno a una "realidad" ausente que se contagia de las voces, conciencias e ideologías que construyen la referencia; esto quiere decir que esa misma realidad a la cual se refiere el discurso es un construcción; por tanto, si nos atenemos a una visión constructivista, no hay realidad extrasemiótica, el lenguaje es una mediación que sustancia cualquier actividad humana, lo que nos induce a pensar que estamos condenados al sentido como travesía histórica desde los imaginarios a las ideologías y los valores culturales. En quinto lugar, que, más que aludir a la verdad, el lenguaje es un dispositivo semiótico cuyo papel consiste en crear efectos de realidad (verdad, validez, certeza, corrección, pertinencia, plausibilidad, probabilidad, verosimilitud, posibilidad) y proponer las condiciones de legitimación de su hacerhacer (manipulación) o su hacer-creer (persuasión). En sexto lugar, que desde la teoría de la acción, el lenguaje no es pasivo, no es el reflejo de algo que lo trasciende; aunque parezca paradójico, el lenguaje sirve a la pasión como complejo de expresión corporal e instrumento de deseo. En séptimo lugar, que los aparatos discursivos mediante los cuales se produce la referencia no tienen límites estrictos y tampoco mantienen una distancia mayor de la gramática como aparato sistemático que los sostiene. En fin, el poder constituyente de sujetos discursivos y la construcción de la realidad (Goodman, 1990) ponen en evidencia la naturaleza constructiva y reconstructiva del lenguaje.

Estaenumeraciónuntantocaóticamarcaunadistancia frente a la racionalización moderna, el distanciamiento dramático entre el sujeto y el objeto, la reificación de la realidad como sustento de lo positivo y la desaparición e impersonalización del sujeto. ${ }^{7}$ En estos frentes se apoyan la cultura científica, el orden social y la libertad individual, como promesas de una visión de mundo que pretende hacer coincidir la acción humana y el orden del mundo, la ciencia y sus aplicaciones, la vida social y las necesidades e intereses de los individuos.

La racionalidad moderna, siendo profundamente ideológica, no siempre reconoce las múltiples paradojas que la atraviesan. Racionalización y subjetivación, diferencia y exclusión son condiciones de un mundo racional para un sujeto trascendental que, obediente al gobierno de la razón, desconoce y estigmatiza otras formas de vida y cultura contra las

7 En términos de Touraine (2000, p. 204), el proyecto dualista de la modernidad coincide con un mundo sin actores y sin acciones, donde la realidad es el terreno firme e imprescindible del orden positivo racional. Esta ausencia de sujeto no concilia con el sentido, pues su presencia pone condiciones que enriquecen la representación mediante la aparición de campos que se refieren a la certeza, la verosimilitud, la probabilidad, la validez, la corrección, la posibilidad, etc., que, en distinta medida operan en la argumentación. 
cuales hay que argumentar: el mito, la magia, la tradición, los imaginarios, las ideologías, las religiones, la poesía, etc., pretensión que, en el momento, es necesario desmentir.

De manera específica, la actitud que reflejan los argumentos formulados pretende, también, poner distancia frente a la equivalencia logocéntrica entre significado y concepto que, afianzada en el signo, fortaleció la guarnición lógica de la representación para que, desde allí, se hablara de la verdad demostrada y de la visión positiva del mundo. Estas ejercen presión sobre los modos de conocer y actuar del ser humano como sujeto encarnado, corpóreo, puesto en situación, capaz de convertirse en actor y en puntal de valores que configuran sentido.

Cabe concluir que la argumentación revive la atención al papel constituyente del lenguaje con respecto a la realidad y al sujeto; estos dos principios se revelan fundamentales a la hora de trabajar el discurso argumentativo. Por un lado, la realidad es el mundo conocido y valorado, lo que significa que el sentido no puede abordarse desde la dicotomía objetivo / subjetivo; por el otro, el sujeto marca con su retorno la vuelta a la acción y la recuperación del ser humano como sujeto discursivo. Por tanto, el sentido es una travesía por los imaginarios, los símbolos, los conocimientos, los saberes, las ideologías y los valores (Cárdenas, 2004, 2007, 2009), en los cuales, además del sustrato lógico, encontramos un sinnúmero de ingredientes de corte expresivo e interactivo que implícitamente lo recorren y exigen reconocer la diversidad, las posibilidades y modalidades que lo configuran.

Dadas la diversidad y la inclusión, los componentes -objetivo, interobjetivo, intersubjetivo y subjetivo- de la relación yo-otro-mundo se tornan solidarios. Dicha solidaridad se manifiesta en los aspectos estructurales, conceptuales, valorativos e ideológicos del discurso argumentativo, en el cual se nos revela un complejo de acciones del que dependen la organización sistemática de la significación textual que, en la puesta en escena del lenguaje, establece condiciones contextuales para diversificar la enunciación.

Por eso, cuando se enuncia el discurso, se producen instancias referenciales que aluden a la realidad, en alguna de sus manifestaciones: el mundo, la acción, la enunciación, el lenguaje mismo. El mundo, con sus atributos de realidad construida, es una referencia pragmática que arrastra la impronta de lo humano. Esta produce sentido mediante procedimientos orientados a dar nombre a las cosas, conceptualizar, categorizar, sistematizar y modelar los hechos, procesos y fenómenos que ocurren a nuestro alrededor; hacer demostraciones y probar hipótesis; describir, analizar e interpretar hechos; sistematizar información, asignarle cierta clave estilística; enfatizar ciertos aspectos; elegir formas expresivas en detrimento de otras; asumir diversos puntos de vista; modalizar grados de conocimiento; sesgar la mirada de acuerdo con un interés de grupo o particular. Estas formas de dar sentido aparecen de diversas maneras y en grado distinto en la argumentación.

De aceptar la diversidad de la representación, es fácil concluir que, en el ámbito pedagógico la argumentación ya no puede obedecer exclusivamente a la verdad demostrada; tampoco puede convertirse en una manera de consolidar contenidos declarativos (especificidad de objetos, hechos o procesos, relaciones, funciones, taxonomías, características a través de conceptos, niveles, etc.) ni concentrarse en la enseñanza de la ciencia. Por eso, al trabajar pedagógicamente la argumentación se ha de considerar que la representación incluye procesos que se realizan con esos contenidos - reflexión, razonamiento, análisis, categorización, inferencia, demostración, comprobación, argumentación, explicación, interpretación-, lo que supone contenidos cognitivos que, adosados a procesos de razonamiento e inferencia contribuyan a la enseñanza del pensamiento 
como fin educativo primordial; al afianzamiento de operaciones, procedimientos y decisiones con respecto a contenidos procedimentales que suponen formas de controlar y transformar el mundo o aplicar conocimientos en otros campos, los cuales tampoco son neutros. En últimas, se trata de la capacidad de toda persona para adoptar posiciones, asumir actitudes, poner énfasis, elegir temas y enfoques, proponer puntos de vista cuya escenificación discursiva permite hablar de contenidos actitudinales, valorativos, que también se escenifican en la argumentación.

Concebida de esta manera, la argumentación revela la heterogeneidad de la acción humana, la diversidad del sentido y contrarresta las pretensiones de reducir el proceso al sistema, el discurso a la comunicación o el sentido a la representación lógica. De ahí el alcance de esta propuesta tendiente a superar los límites del positivismo y del racionalismo, así como de cualquier pragmática que no sea la resultante de una visión integral de la semiosis y el discurso.

Como se puede ver, argumentar es producir sentido a través del juego discursivo entre signos, códigos y textos. Es producir discursos en los que se tejen intertextos, interdiscursos y antidiscursos. Es valerse de los mecanismos sintáctico, semántico y pragmático del sentido. Es acudir a los órdenes referenciales: argumentativo, narrativo, retórico y enunciativo. Es apoyarse en los poderes: técnico-científico, ideológico social y mágico estético del lenguaje. En fin, es atender a la distribución informativa que afecta los órdenes gramatical y temático y a enunciados que modalizan ${ }^{8}$ la carga proposicional. Esta síntesis contempla varios dispositivos por los que transita el sentido, los cuales no pueden ser descuidados por el maestro a la hora de trabajar pedagógicamente la

8 Además de los adelantos previstos en la bibliografía, remitimos al lector al volumen que propondrá un marco semiodiscursivo y sociocognitivo para la enseñanza del lenguaje. argumentación, en cuanto implican ir más allá de la gramática, permitir actuar a los sujetos discursivos relativizar la verdad y abrir el universo del sentido de manera holística, transversal y transdisciplinaria.

\section{Discurso y argumentación}

Si la argumentación es una manifestación estratégica del discurso y este solo se comprende en el terreno de los enunciados, cabe señalar que cuando comparecen los sujetos discursivos sus proferencias entran en un juego dialógico y participativo que hace imposible borrar el sinnúmero de índices que armonizan en la comunicación discursiva; "[...] los enunciados presuponen la existencia de otros (en relación con el hablante) miembros de una comunicación discursiva". Para Bajtín (1982): "Las relaciones entre enunciados enteros no se someten a una gramaticalización porque, repetimos, son imposibles de establecer entre las unidades de la lengua, ni a nivel del sistema de la lengua, ni dentro del enunciado" (p. 261).

Esta relación enunciativa genera discurso, cuando intervienen los sujetos ${ }^{9}$ discursivos; por eso, el primer rasgo que delimita un enunciado es el cambio de los sujetos discursivos. Este cambio enmarca al enunciado y crea una red textual con otros enunciados que cargan sobre sí marcas estilísticas, visiones de mundo, aspectos, modalidades, puntos de vista

9 Todo lo que el ser humano realiza, su actividad humana en cuanto tal, obedece a la naturaleza del acontecimiento. El sujeto como ser en evento (ser-hacer) es sujeto moral que no tiene escapatoria, no tiene coartada (Bajtín, 1997, p. 7), en la medida en que, al estar inserto en la cultura, no puede ser iniciador de nada dada su caducidad, su finitud. Su moralidad proviene de su capacidad de respuesta al otro en condiciones históricas definidas. El sujeto es el hombre real, encarnado, que convive con otros hombres y actúa frente a ellos y en relación con ellos, mediante respuestas variadas, heterogéneas, irrepetibles, totalmente imputables. El sujeto es el ser singular, histórico que vive y muere, es el ser en el cual transcurre el acto único y responsable, abierto a la posibilidad, a lo que todavía no es. 
e intenciones específicas que los individualizan y marcan fronteras entre ellos. Esa masa enunciativa se orienta hacia el otro con determinados propósitos de respuesta recíproca, de réplica, de educación, de persuasión, de comentario, de declaración, etc., y se precisa como un todo absoluto e irrepetible.

A este rasgo, se agrega la conclusividad del enunciado que se produce cuando se agota el objeto del sentido, visible tanto en la intencionalidad (Cárdenas, 2012a, p. 117) como en la intención del enunciado. Por eso, el discurso puede "ser contestado" $y$, en cuanto indica una toma de postura, exige del otro una determinada posición argumentativa. Sin embargo, es la orientación temática la que define ese todo realizable en condiciones específicas de interacción discursiva; así, el discurso desarrolla una de las posibilidades del sentido-objeto. En cuanto a la intención, obedece a la voluntad discursiva del hablante que demarca sus límites; pero el enunciado siempre nos antecede como totalidad, tanto como esquema genérico como por su intención discursiva (Bajtín, 1982, p. 276).

A eso, se suma la expresividad propia del contacto activo de la lengua con la realidad, ya se trate del mundo, la sociedad, la cultura, los hablantes, el lenguaje mismo, factores que entran a hacer parte de la situación discursiva. Entre otras cosas, porque las palabras se toman de otros enunciados que oímos en situaciones específicas de la vida social, a las cuales responden pragmáticamente los géneros discursivos. En consecuencia, la expresividad se inscribe dentro de

[...] los géneros que corresponden a las situaciones típicas de la comunicación discursiva, a los temas típicos y, por lo tanto, a algunos contacto típicos de los significados de las palabras con la realidad concreta en sus circunstancias típicas. De ahí se origina la posibilidad de los matices expresivos típicos que “cubren las palabras". (Bajtín, 1982, p. 277)
En este marco enunciativo se mueve la argumentación. De ahí que los educadores no deban pasar por alto que, de la misma manera como asimilo en grado diverso la palabra ajena, tomo posturas frente a ella con diferentes grados de alteridad (padre-hijo, maestro-alumno, esposo-esposa). La palabra ajena (la de los libros y manuales escolares, la de los expertos educativos y la de las normas y decretos legislativos sobre la educación) me llega cargada de ideologías, conciencias, voces, puntos de vista, modalidades, expresividad $y$, en diversa medida, la devuelvo, cargada de los ecos de la cadena de enunciados de la que hace parte; de la carga valorativa del sobreentendido en que me muevo; de diferentes intertextos e interdiscursos; de los enunciados de maestros, grupos e instituciones a los cuales completa, responde, refuta, presupone, toma en cuenta de alguna manera; $y$, en diferente grado dialógico (conversación, discusión, polémica, refutación), en el marco de una formación discursiva (Foucault, 1970).

Esta doble expresividad de la palabra ajena (mis acentos y los acentos del otro) puede ser explícita o implícita, tener diferente grado de otredad o diferente grado de referencia: hacia el objeto, hacia otros enunciados, hacia otros sujetos, hacia el sobreentendido cultural. Tal acción argumentativa obedece a que los sujetos discursivos no hablan de todo en cualquier circunstancia ni desde todos los puntos de vista. Además de los límites perceptivos e históricos, ningún sujeto es capaz de abordar el objeto desde todas las perspectivas, no puede agotar solo su sentido, siempre está en lucha mortal por la extraposición (Bajtín, 1982, p. 22). Es este accionar el que precisamente define la naturaleza del sujeto como actor discursivo.

El tercer factor corresponde a las formas genéricas del enunciado. La elección del género depende de varios factores: de la esfera discursiva, de las opciones temáticas, de la situación concreta y de los participantes, cuya intencionalidad se circunscribe, se 
forma, se adapta y se desarrolla en torno al género discursivo. En esta condición, el discurso pone en escena determinados géneros (exposición, conferencia, ponencia, taller, seminario) y configura el marco de las posibilidades comunicativas como resultado del manejo del repertorio de géneros, cuyo uso depende de la práctica discursiva, de la inmersión en los hechos de lenguaje: hablar y escuchar, leer y escribir, pensar y hacer. Por eso, puede afirmarse, de acuerdo con Bajtín (1982) que: "Aprender a hablar quiere decir aprender a construir los enunciados (porque hablamos con los enunciados y no mediante oraciones, y menos aún por palabras separadas)" (p. 268).

En consecuencia, aprender a argumentar es, en últimas, aprender a manejar géneros propios de una formación discursiva que sirve de fondo a la argumentación: ensayo, artículo, ponencia, conferencia, comentario, discusión, sustentación, exposición, explicación, etc. Esta lección pragmática formativa requiere que nuestro discurso, además de plasmarse en formas genéricas (Bajtín, 1982, p. 268), incorpore estrategias comunicativas que nos ayuden a situarnos en el discurso ajeno, oír sus puntos de vista, apreciar sus argumentos, identificar sus fundamentos, precisar sus categorías, clarificar sus estructuras cognitivas, adivinar sus intenciones, percibir su desarrollo temático, intuir sus pretensiones, prever su final, etc., a tal punto de ser capaces de encontrar la contrapalabra adecuada a las pretensiones argumentativas.

Entonces, la naturaleza del discurso se define, según Bajtín (1982, p. 260), por el enunciado como unidad real de la comunicación, cuyos rasgos distintivos son su carácter dirigido a un destinatario, sus marcas genéricas y sus marcas expresivas referentes a la temática, el estilo y la composición.

\section{Discurso, mediación y argumentación}

El universo complejo del lenguaje por el cual hemos discurrido nos invita a retomar el tema de la mediación, por el sinnúmero de implicaciones pedagógicas que tiene con respecto a la argumentación. $\mathrm{Si}$ aceptamos que el sentido es una travesía divergente desde los imaginarios a las ideologías, tanto Bajtín (1992) como Vygotsky (1989) se ubican en el campo social desde donde es posible plantear que el discurso es un producto mediado por un espacio dual, ambivalente, donde intervienen varias voces y se manifiesta el conflicto ideológico, el choque de culturas entre lo individual y lo social. Esta especie de colisión intersubjetiva tiene su raíz en el discurso y la manera como se posiciona en el seno de la lengua como construcción social significante que, históricamente, condensa el conflicto de la palabra, genera enunciados que se alimentan de otros textos y hace pleno el dialogismo de la palabra de los interlocutores.

Tal como se dijo más arriba, el conflicto discursivo que nutre la argumentación echa raíces en la total ausencia de neutralidad del hombre frente al mundo real. Los seres humanos asumen posturas y adoptan actitudes a partir de la experiencia que tienen de las cosas; la experiencia se hace plena en la medida en que las vivencias se llenan de sentido, de valor, lo que nos provee la realidad como mundo conocido y valorado (Bajtín, 1986). El contenido valorativo cognitivo, ético y estético forma un complejo mediador que organiza un horizonte regulativo de experiencia humana y transforma la información acerca del mundo en discurso, en cuya travesía se va desplegando el sentido de lo que son las posibilidades humanas.

Esta complejidad pone en evidencia que la mediación semiótica del lenguaje transforma sustancialmente el conocimiento y la conducta, que no son un simple reflejo de lo que ocurre en la realidad sino un proceso transductivo (Cárdenas, 2011b) de la construcción psicosocial de los sujetos. La evidencia reguladora del lenguaje se hace visible cuando las vivencias se convierten en experiencia, la experiencia se transforma en conocimiento y en conducta y todo 
ello confluye en acción humana teñida de pasión. En este recorrido se revelan huellas, signos, señales, indicios de un tránsito que hace del sujeto de lenguaje una forma del acontecer humano, cuyo comportamiento se regula y equilibra (Martín Serrano, 1977), en la medida en que se sitúa en el terreno de la praxis intersubjetiva, interobjetiva e intercultural, la cual genera una imagen significativamente enriquecida del mundo. A ese despliegue no escapa el lenguaje que crea su propia autorreferencia visible en la autorreflexión que propicia el aparato retórico. ${ }^{10}$

Debido a esta triple mediación cognitiva, social y autorreferencial, el lenguaje deja de ser simple instrumento y asume ser mediador semiótico y discursivo que, más que hacia un objeto externo, se orienta hacia la acción inscrita en los modos de conocer y comportarse de sujetos humanos y hacia sus propias operaciones lingüísticas. Esto enriquece los códigos de sentido, cargándolos de contenido y de valor, de forma que resultan sustancialmente transformados el mundo, el hombre como sujeto y el lenguaje mismo.

El papel integrador y regulador es visible en la construcción de la referencia contextual y no contextual, en la perspectiva de Vygotsky, en la que los signos sirven a la reflexión abstracta y generalizada, en tanto que los índices apuntan al contexto (Wertsch, 1985, pp. 139-168). En el primer caso, los signos distancian el pensamiento, mientras que los indicios organizan la actividad psíquica incorporando a los sujetos - copartícipes e interactuantes - en situación ambital y estableciendo amarres contextuales que, a la vez que concentran la atención en el objeto referenciado, enganchan la acción comunicativa a la

10 Además de los aparatos discursivos - enunciativo, narrativo, retórico y argumentativo- (Charaudeau, 1983, pp. 58-81), la mediación se hace visible a través de los géneros y poderes discursivos, las estructuras y niveles semióticos, las estructuras y operaciones cognitivas, y las funciones significativa, comunicativa y expresiva del lenguaje. experiencia actual de enunciación, tal como ocurre en la argumentación.

Este juego discursivo de distancias mediáticas flexibles nos advierte que el signo, en general, es una mediación psíquica, sígnica y pragmática entre un significante y un significado. Este último, más que identificarse con el concepto y su capacidad para abstraer y generalizar, abre tránsito al sentido mediante códigos que asumen relaciones, funciones y operaciones en contexto y están cargados de valor. Este dispositivo encarna una evidencia: el uso discursivo del lenguaje no puede separarse de los valores que de manera natural lo acompañan (Bajtín, 1992). Dicha situación no puede pasarse por alto en la pedagogía del lenguaje; los procesos de formación se someten al flujo axiológico del sentido, cuando usamos los signos para abstraer, generalizar, indicar, identificar, denominar, evocar, comparar, analizar o inferir; es decir, cuando realizamos operaciones discursivas o cuando creamos analogías o adoptamos cierta perspectiva ante la realidad, ya sea para producir conocimiento, para comunicarnos con los demás o para expresar nuestra vida interior. Si en nuestra mente no hay un reflejo correlativo de la realidad, es porque no disponemos de un correlato positivo de ella, salvo su configuración como mundo vivido y experimentado culturalmente, en el que el hombre ha puesto su acción y configurado su experiencia, llenándolo de vivencias y representándolo según sus puntos de vista y perspectivas.

Sin duda, este planteamiento contrasta con los ideales tras los cuales marcha la educación en su intento de sujetar, culturizar al individuo, encauzar o sosegar las fuerzas que bullen en el contexto de sus relaciones con el mundo, consigo mismo y con los demás. Si de algo debe ocuparse la educación es de formar la conciencia de la situación compleja en la que siempre el hombre se encuentra con la diferencia, para que esta no le sea indiferente y la pueda asumir de manera responsable y en su diversidad dialéctica, 
analéctica (Babolín, 2005; Oñativia, 1978) y dialógica (Cárdenas y Ardila, 2009).

La diversidad no es asunto solo de conciencia e intención; es un problema de complejidad del mundo, de tener a la mano numerosos ángulos de referencia, de representación múltiple, de pluralidad de puntos de vista y de contenidos, de numerosas situaciones en las que el ser humano actúa sus prácticas sociales. Desde estos factores es posible hablar de la comprensión como pretensión básica de la pedagogía del lenguaje, en la cual la argumentación puede propiciar la actividad constructiva que sustente los cambios de conocimiento y conducta de los estudiantes. Por eso, se requiere que la comprensión se abra a la explicación y la interpretación (Vygotsky, 1989), para que, siguiendo a Bajtín (1997), la educación se oriente hacia el aprendizaje deliberado y responsable.

La convergencia enunciativa de la argumentación conforma la mediación como un saber/querer/poderhacer-ser discursivo, en su travesía por el sentido a través de imaginarios, simbolismos, saberes, valores e ideologías ${ }^{11}$ (Van Dijk, 2000). Así, la función mediadora del lenguaje, más allá de sus trazas referenciales, es acción (Echeverría, 1997) y poder de mención y afluencia de operaciones y miradas que coordinan las capacidades humanas y las disponen al servicio de la comprensión, tanto hermenéutica como heurística del sentido como problema.

Dado este panorama, la argumentación es un proceso discursivo que multiplica las versiones de la lógica, mediante el cual se ejercen con eficacia diversas

11 La ideología instala al hablante en un terreno histórico-social que constituye el horizonte de lo percibido y sirve como patrón de referencia a lo contemporáneo. La ideología nos presenta el mundo como un conjunto infinito de posibilidades, pero les impone una norma, unos principios, unas maneras de verlo, unos puntos de vista específicos. formas de control social, se enriquecen y dinamizan las culturas, afluyen diversas fuentes de significación, se organiza la realidad en múltiples niveles, proliferan las maneras de representar, se multiplican los saberes. En fin, la argumentación diversifica la experiencia humana y, a partir de un presente enunciado, abre las posibilidades contextuales del sentido para exigir a los sujetos discursivos poner su empeño en diversas formas de pensar, razonar y actuar. En otros términos, la argumentación disocia simbólicamente la realidad para objetivarla y convertirla en el avistamiento de un sujeto que la orienta y llena de contenido valorativo, transformándola en algo valioso dentro de la cultura, infundiéndole dinámica al conocimiento y a la conducta, reorientando la acción y matizándola con la pasión; en fin, poniendo en escena la recursividad discursiva del lenguaje que, como se evidencia, es irreductible a lo verbal.

\section{Texto, comprensión y argumentación}

El texto es, desde el punto de vista sociocultural, una manera de organizar la materia significativa en varios planos de representación. Estos obedecen a un juego entre lo implícito y lo explícito que justifica la incorporación de los matices lógico y analógico del conocimiento, que dinamizan la riqueza semiótica de los signos, códigos y textos que nos inclinan a aceptar la extensión del sentido más allá de los límites de la verdad y la importancia del trabajo retórico que el lenguaje efectúa sobre sí mismo. Si bien este trabajo es visible en los procedimientos, operaciones, transformaciones y referencias, vamos a concentrar nuestra atención en la naturaleza del texto como proceso, en los términos de Bajtín (1982, 1992).

El texto es un enunciado compuesto por signos orientados dialógicamente al sentido, que lo hacen único e irrepetible y lo convierten en acontecimiento. Al acontecer, el texto se convierte en un eslabón más en la cadena de otros textos escritos y orales, anteriores y posteriores, endiálogoabiertohacia elfuturoconotros 
textos. En esta dirección, el texto sigue madurando, dando lugar a su gestación mediante, por ejemplo, el sobreentendido o sobre el discurso referido. Este trabajo revela sentidos que pueden estar de manera oculta, potencial, los cuales reaparecen cuando nos situamos de manera activa en la cultura, actuamos en nuevos contextos, o a través de la cita, la selección de fragmentos, la alusión, la traducción, etc.

Siguiendo a Bajtín, la cuestión textual se da en términos de producción y de comprensión de sentido, lo que pasa por ser un proceso acerca de lo planteado (no dado) que incorpora la intersubjetividad y la interdiscursividad como manifestaciones fenoménicas. El texto, como el sujeto que lo produce, se ubican en el centro de fuerzas centrífugas que intentan evitar su conclusión, pues como objeto planteado siempre se da en la no coincidencia entre el yo y el otro. Esto nos da evidencia de que el texto no se define por sí mismo, sino desde la extraposición, como una forma de provocación que se nos hace desde la mirada del otro. Así, un texto está unido a la existencia de otro, a través de la acción de sujetos que en su ser acontecer lo transforman en acontecimiento, lo transfieren al plano del deber ser, al plano de otros sentidos y otros valores que están por llegar a ser.

De ser esto así, el texto argumentativo es una forma del acontecimiento por medio del cual se plantea el sentido como refracción que, al entrar en contacto dialógico, sufre el contagio de otros textos, otros géneros y otras lenguas; se tiñe de acentos, voces, conciencias, valores e ideologías. Esta fluctuación fronteriza exige comprensión pues, en cuestión de textos, no existen el alfa y el omega, no hay un texto de textos, definitivo y único, al cual pueda ser traducido otro texto hasta el final. En lo que concierne a la argumentación, el texto es tan fronterizo como el enunciado, "[...] siempre se desarrolla sobre la frontera entre dos conciencias, dos sujetos" (Bajtín, 1982, p. 297. El énfasis es añadido). Esto importa en la instauración y reconocimiento de la diferencia entre los sujetos discursivos y, por tanto, en la búsqueda de la contrapalabra, que es la forma mediante la cual la comprensión exige la argumentación.

Siguiendo estos lineamientos, el texto argumentativo no es un objeto totalmente concluido. Por eso, cuando se argumenta se ponen en relación dialógica el yo y el otro, mediante este y otros textos. Esta confrontación de textos que resulta ser la argumentación propone el sentido como producción de valores puestos en discurso, que gira en torno a la expresión y a la interacción. En este plano, el texto argumentativo, a pesar de obedecer a la singularidad del autor, siempre apunta a lo otro, llámese lector, tradición cultural o sobreentendido que es, como ya se dijo, el conjunto polifónico de saberes compartidos, de voces acalladas que aún no han tenido la palabra que las exprese, que las manifieste. Esto es comprensible desde la perspectiva de Bajtín, para quien el texto adopta cierta personalidad, ${ }^{12}$ se comporta como un otro que entra a dialogar con otros textos, otros discursos, otros sentidos, para configurar una red heterogénea donde prevalece la palabra reacentuada ${ }^{13}$ del otro.

\section{Conclusiones}

Los nexos entre la argumentación, el pensamiento y el discurso dan sustento, por una parte, a la tesis acerca de los procesos pedagógicos del lenguaje - la

12 En este caso, podría hablarse de la capacidad delocutiva del texto, mediante la cual este, además de su capacidad argumentativa y narrativa, participa del aparato enunciativo, que, por momentos, da lugar a la aparición del metatexto.

13 Para Bajtín (1997): "La entonación siempre se encuentra en el límite entre lo verbal y lo extraverbal, entre lo dicho y lo no dicho. Mediante la entonación la palabra se relaciona directamente con la vida. Y ante todo, justamente en la entonación el hablante se relaciona con los oyentes; la entonación es social por excelencia. Es sobre todo sensible para con cualquier oscilación de la atmósfera social en torno al hablante" (pp. 118-119). 
enseñanza del pensamiento, la interacción, la lectura y la escritura - y, por otra, respaldan la necesaria coherencia de los planteamientos acerca de las formas lógica y analógica del conocimiento (Cárdenas, 2007), así como de las facetas analítica, crítica y creativa del pensamiento dentro del marco semiodiscursivo acordado para nuestra investigación (Cárdenas, 1997, 2000b). Aún más, muestra que los sujetos enunciadores argumentan porque, puestos en situación discursiva, no tienen otra alternativa que extraponerse frente a los demás, asumir posiciones, adoptar puntos de vista y decir del mundo desde determinada perspectiva. Este decir no siempre se verifica en los límites estrictos de la verdad, cualesquiera sean sus apoyos: adecuación, coherencia o consenso.

Por eso, a la hora de educar en la argumentación, es preciso tener en cuenta el distanciamiento frente al objeto, lo cual quiere decir que cuando argumentamos siempre lo hacemos en torno a un él, un tercero que participa de los actos de lenguaje y frente a otro, condición de doble alteridad que no se puede pasar por alto. Para ello nos apoyamos, básicamente, en operaciones de distinto orden que tocan tanto lo cognitivo como lo lingüístico. Asimismo, es preciso considerar que al argumentar nos situamos en la perspectiva del otro, del discurso ajeno desde donde el acontecimiento textual se produce como un saber refractario, lleno de voces, conciencias e ideologías que confieren a la argumentación su naturaleza polifónica.

En esa condición, la argumentación materializa estructuras mentales y formaciones ideológicas, generando un espacio de convergencia y de conflicto entre los discursos, gracias a lo cual se mantienen en permanente interacción dialógica los puntos de vista sobre los que se discute. Además, recontextualiza enunciados diferentes para impedir que se anquilose el significado, y lo devuelve al tinglado social donde los sujetos discursivos viven el conflicto propio de su diferencia no indiferente (Bajtín, 1997), en sus maneras de ser y su hacer discursivo y de responder a las reglas que rigen lo que se puede y debe decir en circunstancias específicas.

Desde aquí se hace visible la integración cognitiva (Martín Serrano, 1977) de los campos orgánicos del sentido - lógico y analógico-, los cuales configuran las visiones dialéctica, analéctica y dialógica (Cárdenas, 2012a, p. 49) en cuya intersección se producen el conocimiento y el comportamiento, cosa que no ha de descuidar la pedagogía del lenguaje. Si en torno a esta integración no desatendemos la dimensión dialógica, es fácil consolidar un diagrama en el que se superponen en diferentes grados lo dialéctico (síntesis), lo analéctico (sincretismo) y lo dialógico (discrepancia). Tal diagrama ilustra el campo de la praxis donde el hombre vive e instala la diferencia no indiferente. En este territorio limítrofe se multiplican las formas (nociones, conceptos, imágenes, símbolos, indicios) que tensionan la vida del hombre, donde, a falta de definiciones, la vida y la cultura se alimentan del conflicto y la disonancia que son la levadura que fermenta la experiencia humana.

Esta progresión transversal de la argumentación es básica en la educación porque el discurso argumentativo es acción mediadora y proactiva que moldea la actividad humana, en cualquiera de los dos campos de la alteridad: el otro o la cultura y el conjunto de acciones que allí se desarrollen. Por eso, la argumentación se ha de enriquecer con las operaciones primarias (Cárdenas, 2000b) de base analógica, con el fin de promover las actitudes y entroncar con el simbolismo propio de la cadena ética y estética que lleva de las vivencias a los sentimientos y atraviesa la construcción intersubjetiva e interobjetiva del sentido.

Dado que el sentido no es algo dado sino planteado y está en permanente proceso de producción, cabe a los maestros la responsabilidad argumentativa de pensar que cada vez que se elabora un texto se crea una relación dialógica con otros sujetos y textos de 
manera que, a la par que los interroga, formula sus propias respuestas marcando con ello el paso histórico que reconoce o desconoce un texto, que recuerda o echa en el olvido sus planteamientos, su decir. Desde ahí es posible aprovechar la polifonía para pensar la educación inclusiva y diversa, apoyada en puntos de vista, perspectivas, enfoques, marcos de conocimiento, modalidades de saber, etc., entre los cuales reinan la discrepancia, el conflicto. Sin duda, la argumentación es un buen pretexto educativo para cambiar la historia de las sensibilidades, de la imaginación, del intelecto, así como de los modos de pensar, de las visiones de mundo. Este cambio también puede afectar tanto las concepciones sobre la realidad y el ser humano como sobre el lenguaje.

\section{Reconocimientos}

Este artículo es el resultado de la investigación DLE033-99, patrocinada por la Universidad Pedagógica Nacional.

\section{Referencias}

Bajtín, M. M. (1982). Estética de la creación verbal. Madrid: Siglo XXI.

Bajtín, M. M. (1986). Problemas literarios y estéticos. La Habana: Arte y Literatura.

Bajtín, M. M. (1992). El marxismo y la filosofía del lenguaje. Madrid: Alianza.

Bajtín, M. M. (1997). Hacia una filosofía del acto ético. Barcelona: Anthropos.

Babolín, S. (2005). Producción de sentido. Bogotá: Universidad Pedagógica Nacional, San Pablo.

Beuchot, M. (1997). Tratado de hermenéutica analógica. México: Universidad Nacional Autónoma de México (UNAM).
Bronkart, J.P. y otros. (1985). Vygotsky aujourd'hui. París: Delachauz y Niestlé.

Bruner, J. (1989). Realidad mental y mundos posibles. Barcelona: Gedisa.

Cárdenas Páez, A. (1997). Hacia una pedagogía integral del lenguaje. Folios, 7, 33-42.

Cárdenas Páez, A. (2000a). Un marco semiodiscursivo y sociocognitivo para la enseñanza del español. Informe de investigación, Centro de Investigaciones de la Universidad Pedagógica (CIUP).

Cárdenas Páez, A. (2000b). Naturaleza semiótica del pensamiento y pedagogía del lenguaje. En B. C. Barbosa Alonso (comp.), El oficio de investigar: educación y pedagogía hacia el nuevo milenio (pp. 189-224). Bogotá: Universidad Pedagógica Nacional (UPN), Centro de Investigaciones de la Universidad Pedagógica (CIUP).

Cárdenas Páez, A. (2004). Hacia una pedagogía de la literatura. Bogotá: Universidad Pedagógica Nacional.

Cárdenas Páez, A. (2007). La escritura y la argumentación”. RedLecturas (Medellín, Gobernación de Antioquia), 2, 221-231.

Cárdenas Páez, A. (2009). Literatura, pedagogía y formación en valores. Enunciación, 14 (2), 5-20.

Cárdenas Páez, A. (2011a). Lenguaje, razonamiento y educación. Innovación Educativa (Instituto Politécnico Nacional [IPN], México), 55, 44-54.

Cárdenas Páez, A. (2011b). Piaget: lenguaje, conocimiento y educación. Revista Colombiana de Educación (Universidad Pedagógica Nacional, Bogotá), 60, 71-91. 
Cárdenas Páez, A. (2012a). Elementos para una pedagogía del lenguaje. Bogotá: Universidad Pedagógica Nacional.

Cárdenas Páez, A. (2012b). Lenguaje, sentido y cultura. En D. L. Torres (comp.). Lecturas y escrituras. Lecciones doctorales (pp. 37-66). Tunja: Universidad Pedagógica y Tecnológica de Colombia (UPTC).

Cárdenas Páez, A. (2012c). Lenguaje y pedagogía de la interacción: actitudes y valores. En S. Soler $e t$ al. (comps.). Investigación y pedagogía del lenguaje. Bogotá: Universidad Distrital Francisco José de Caldas, Doctorado Interinstitucional de Educación (DIE).

Cárdenas Páez, A. y Ardila, F. (2009). Lenguaje, dialogismo y educación. Folios, 29, 27-50.

Charaudeau, P. (1983). Langage et discours. Eléments de semiolingüistique. París: Hachette.

Correa, J. I. et al. (1999). Saber y saberlo demostrar. Bogotá: Universidad Externado de Colombia y Colciencias.

Echeverría, R. (1997). Ontología del lenguaje (4. ${ }^{\text {a }}$ ed.). Santiago de Chile: Dolmen.

Foucault, M. (1970). La arqueología del saber. Madrid: Siglo XXI.

Goodman, N. (1990). Maneras de hacer mundos. Madrid: Visor.

Habermas, J. (1989). Teoría de la acción comunicati$v a$ (I y II). Madrid: Taurus.
Martín Serrano, M. (1977). La mediación social. Madrid: Akal.

Monsalve, A. (1992). Teoría de la argumentación. Medellín: Universidad de Antioquia.

Oñativia, O. (1978). Antropología de la conducta. Buenos Aires: Guadalupe.

Perelman, Ch. y Olbrecchts-Tyteca, L. (1989). Tratado de la argumentación. Madrid: Gredos.

Rojas, C. (2006). Genealogía del giro lingüístico. Medellín: Universidad de Antioquia.

Soler, S. et al. (comps.). (2012). Investigación y pedagogía del lenguaje. Bogotá: Universidad Distrital Francisco José de Caldas, Doctorado Interinstitucional de Educación (DIE).

Torres, D. L. (comp.). (2012). Lecturas y escrituras. Lecciones doctorales. Tunja: Universidad Pedagógica y Tecnológica de Colombia (UPTC).

Touraine, A. (2000). Crítica de la modernidad. México: Fondo de Cultura Económica.

Wertsch, J. V. (1985). La médiation sémiotique de la vie mentale: L. S. Vygotsky et M. M. Bakhtine. En J. P. Bronkart et al. Vygotsky aujourd'hui (pp. 139-168). París: Delachauz y Niestlé.

Van Dijk, T. (2000). Ideología: un enfoque multidisciplinario. Barcelona: Gedisa.

Vygotsky, L. (1989). El desarrollo de los procesos mentales superiores. Barcelona: Crítica. 